\title{
Optimum Design of an AUV by Using Computational Fluid Dynamic Analysis
}

\author{
Ting Gao \\ Tate Key Laboratory of Science and \\ Technology for National Defence of \\ Autonomous Underwater \\ Vehicle,Harbin Engineering \\ University,Harbin 150001,China \\ gaoting880225@163.com
}

\author{
Zhuoyi Yang \\ ${ }^{1 .}$ Tate Key Laboratory of Science and \\ Technology for National Defence of \\ Autonomous Underwater \\ Vehicle,Harbin Engineering \\ University,Harbin 150001, China \\ ${ }^{2}$ Technology Research Century of High \\ Performance Ship, Wuhan University of \\ Technology, Wuhan, China \\ yangzhuoyi@hrbeu.edu.cn
}

\author{
Yaxing Wang \\ State Key Laboratory of Science and \\ Technology for National Defence of \\ Autonomous Underwater \\ Vehicle,Harbin Engineering \\ University,Harbin 150001,China
}

\begin{abstract}
Computational fluid dynamics (CFD) is considered as an effective tool to evaluate the performance of the autonomic underwater vehicle (in short, AUV) with propeller and rudders. This work simulates hull-propeller-rudder interaction under four different general arrangement conditions, and analysis on hull resistance, propeller thrust, torque and efficiency, rudder lift, drag and its ratio. The best layout mode of propeller and rudders is finally determined from assesses the advantages of each program strategy and the actual needs.
\end{abstract}

Keywords-CFD, propeller-hull-rudder Interactions, AUV, design

\section{INTRODUCTION}

With the exploitation of ocean resource and the military need, autonomous underwater vehicles are necessary tools. They are being used increasingly in a wide range of areas such as environmental monitoring, exploration of seabed and hydrographic surveys. So many countries are focusing on the AUV and researching them. AUV provides propulsion energy with various cell, thus endurance of the vehicle and number $f$ sensors is practically very limited due to volume and quality of the battery. In order to maximize the range, much work, however, still needs to be done in terms of optimizing the maneuverability, propulsion and hydrodynamic performance. There are many elements influence these behaviors, this paper will focus on the arrangement of propeller and rudders. Reasonable number and installation position of propeller and rudders will improve the maneuverability and the propulsion system efficiency.

To assess change of the flow around auv when general arrangement is different, predicting characteristics of propeller and hull are all judged to be significant. The experiments are practically very limited due to cost and time reasons. Hence numerical methods, mainly Computational Fluid Dynamics (CFD) ones are more and more often used for such tests.
Nowadays, various CFD analysis methods were investigated to verify their reliability, prior to conducting the test to predict the efficiency of the propeller. In this paper, Fluent one software of CFD is evaluated with the purpose of obtaining the hydrodynamic parameter. Considering the complexity of the flow after hull, I take hull, propeller and rudder as a whole. This work based on sliding mesh technique, RNG k- $\varepsilon$ model and SIMPLE method, researching on mutual interaction of the rudder - propeller - hull of four cases. There have been many researches on interaction of hull and propeller but unfortunately most of them focus on single propeller, rarely involves the comparison of single and double propellers. This work provides technical support for the design of new AUVs and optimization of the propeller.

\section{NUMERICAL METHOD}

\section{A. Governing Equations and Turbulence Model.}

Propeller is to make the rotary motion in fluid field ,besides, propeller hull and rudder effect mutually. So the flow is unsteady in the calculation. This work chooses RANS equation as the based equation. The form as follow:

$$
\begin{gathered}
\frac{\partial \overline{u_{i}}}{\partial x_{i}}=0 \\
\rho \frac{\partial \overline{u_{i}}}{\partial t}+\rho \overline{u_{j}} \frac{\partial \overline{u_{i}}}{\partial x_{j}}=\rho \overline{F_{i}}-\frac{\partial \bar{p}}{\partial x_{i}}+\frac{\partial}{\partial x}\left[\mu \frac{\partial \overline{u_{i}}}{\partial x_{j}}-\rho \overline{u_{i}^{\prime} u_{j}}\right]
\end{gathered}
$$

Where, $\overline{u_{i}}$ is average speed, $u_{i}^{\prime}$ is fuctuating velocity and $\rho \overline{u_{i}^{\prime} u_{j}}$ is reynolds stress.

A RNG k- $\varepsilon$ turbulence model is selected. Compared with standard $\mathrm{k}$-,it takes into account the rotation of the mean flow Through amendments to the turbulent viscosity. This makes it better to deal with the rotating movement of the propeller. The RNG k- $\varepsilon$ model transport equations are explained below: 
$\frac{\partial \rho k}{\partial t}+\frac{\partial}{\partial x_{j}}\left(\rho U_{j} k\right)=-\frac{2}{3} \rho k \frac{\partial u_{k}}{\partial x_{k}}+\frac{\partial}{x_{j}}\left(\frac{\mu_{e f f}}{\sigma_{k}} \frac{\partial k}{\partial x_{j}}\right)+G_{k}-\rho \varepsilon$

$\frac{\partial \rho \varepsilon}{\partial t}+\frac{\partial}{\partial x_{j}}\left(\rho U_{j} \varepsilon\right)=-\left[\left(\frac{2}{3} C_{\varepsilon 1}-C_{\varepsilon 3}+\frac{2}{3} C_{\mu} C_{\eta} \cdot \frac{k \partial_{k}}{\partial \partial x_{k}}\right) \rho \varepsilon \frac{\partial u_{k}}{\partial x_{k}}+\frac{\partial}{\partial x_{j}}\left(\frac{\mu_{e f f}}{\sigma_{\varepsilon}} \frac{\partial \varepsilon}{\partial x_{j}}\right)\right]$

$+\rho \frac{\varepsilon}{k}\left[\left(C_{\varepsilon 1}-C_{\eta}\right) G_{k}-C_{\varepsilon 2} \rho q\right]$

Where,

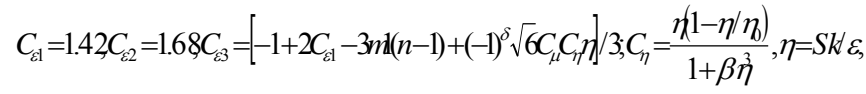

$S=\sqrt{2 \overline{S_{i j} S_{i j}}}, \eta_{b}=4.28 \beta \beta=0.01, C_{\mu}=0.085$

\section{B. Modeling and Grid.}

The AUV researched in this paper is a streamlined torpedo-shaped body with four wings (+stern plane) on its tapered tail, and geometry models are built by using the software ICEM with a scale of 1:1. According to the difference number of propeller, we divide models into two kinds of general arrangements: single propeller and double propellers. About each condition, there are two cases: propeller is assigned before rudder and placed behind rudder.Fig1 shows the four models.

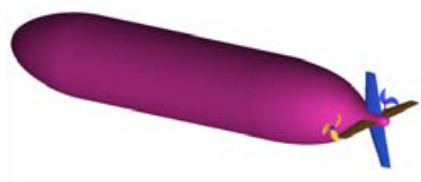

a. propellers before rudders

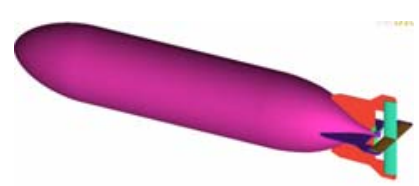

c. single propeller before rudders

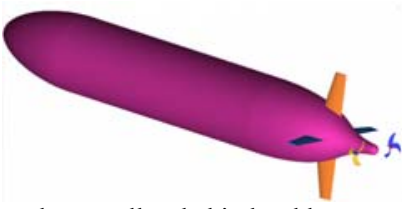

b. propellers behind rudders

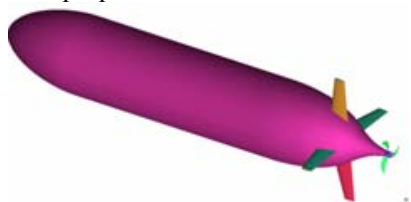

d. single propeller behind rudders
Fig 1. Models of calculation

During the calculation,all models choose the same hull and rudders .Propellers are designed on the basis of diagram and ensure equal thrust under two conditions when propeller palced behind rudder. The parameters of propellers and rudders are shown in table1.

\section{TABLE1 PARAMETERS OF PROPELLERS AND RUDDERS}

\begin{tabular}{|c|c|}
\hline diameter $(\mathrm{mm})$ & $311 / 382$ \\
\hline blade & 3 \\
\hline pitch ratio & $0.62 / 0.51$ \\
\hline $\begin{array}{c}\text { hub diameter } \\
\text { ratio }\end{array}$ & 0.15 \\
\hline $\begin{array}{c}\text { area of a } \\
\text { rudder }\left(\mathrm{m}^{2}\right)\end{array}$ & 0.075 \\
\hline
\end{tabular}

The entire control domain is divided to two domain-inner domain in which the AUV is, andexternal domain which covered the inner domain. In order to simulate propeller rotation, there is a small cylindrical computational domain around the propeller as shown in Fig. 3. It is set as a rotating zone including the propeller and the other are stationary zones.Because the unstructured grid system has better adaptability, it is used in inner domain to generate mesh that about 110000 . And the structured grid system is used in external domain to reduce the mesh quantity which are about600000. The grid of a propeller is 700,000,the total number of grids is 3.2 million.A boundary layer mesh was used to ensure that the non-dimensional normal distance from the auv surface, $\mathrm{y}^{+}$, was suitable. The two domains and grids are shown in Fig. 2 and Fig.3.Using the merged grid feature of Icem software, computational models have the same outer flow field grids.Combined the only external domain mesh with different inner domain grids,making the process modularization, standardization.

\section{Boundary Condition.}

The boundary conditions were for inlet-velocity and outlet-pressure outlet condition, for the AUV surface-wall with no slip condition. The split plane was treated as a sliding interface between rotating and stationary zones.

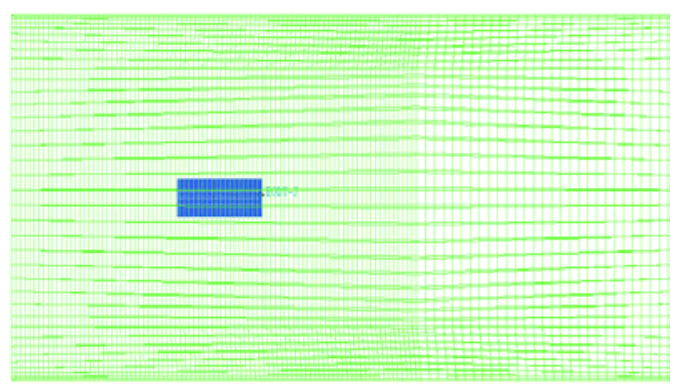

Fig 2. Two domains

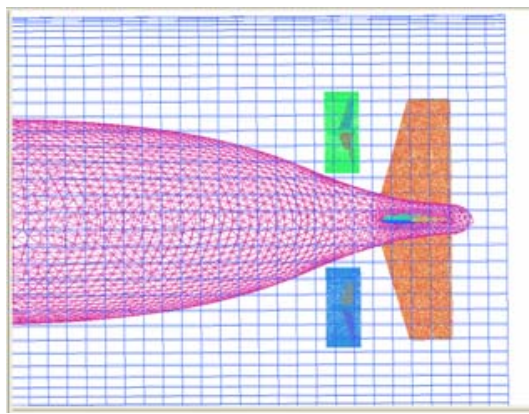

Fig 3. Grids for models

\section{RESULTS AND DiSCUSSION}

In this paper, hull-propeller-rudder interaction under four different general arrangements are simulated. The hull resistance, propeller thrust, torque and efficiency, rudder lift, drag and its ratio are obtained in five rudder deflection angles. They are $0^{\circ}, 5^{\circ}, 8^{\circ}, 12^{\circ}, 15^{\circ}$. 


\section{A. Resistance Performance Calculation.}

In order to quantify the propeller effects under various operating conditions, calculations are performed for the case with and without the propeller. The velocity inlet was set at 1.54 $\mathrm{m} / \mathrm{s}$ and the propeller speed is $11.7 \mathrm{rps}$. Table 2 is the drag coefficient of 0 rudder angle. The results show that the effect of propeller is quite obvious. With a propeller or double propellers the total resistance of the hull will increase more than $13 \%$. The total resistance of hull is composed of frictional resistance around the auv surface and pressure resistance caused by pressure difference of bow and stern. Propeller accelerates flow in front and behind of it resulting in reduced pressure over the rear of the hull and increased pressure resistance. The frictional resistance has a little change, but pressure resistance alters more. The resistance at different rudder deflection angle is shown in Fig.4.

In this work, the angle is only about horizontal rudders. We can see that hull drag is larger for the cases propeller placed before rudders compared with the behind condition, when the number of propeller is same. Furthermore, the effect of resistance on the AUV due to a single propeller is higher than double propellers thanks to a bigger diameter. It is also clear hull drag increases with the angle enlarge.

TABLE 2. COMPARISON OF CALCULATED RESISTANCE COEFFICIENTS WITH AND WITHOUT PROPELLER

\begin{tabular}{|c|c|c|c|}
\hline & $\begin{array}{c}\text { total } \\
\text { resistance }\end{array}$ & $\begin{array}{c}\text { pressure } \\
\text { resistance }\end{array}$ & $\begin{array}{c}\text { frictional } \\
\text { resistance }\end{array}$ \\
\hline Without propeller & 0.011 & 0.0078 & 0.0031 \\
\hline $\begin{array}{c}\text { Propellers before } \\
\text { rudders }\end{array}$ & 0.013 & 0.0094 & 0.0033 \\
\hline $\begin{array}{c}\text { Propellers behind } \\
\text { rudders }\end{array}$ & 0.012 & 0.0089 & 0.0035 \\
\hline $\begin{array}{c}\text { Single propeller } \\
\text { before rudders }\end{array}$ & 0.013 & 0.0100 & 0.0035 \\
\hline $\begin{array}{c}\text { Single propeller } \\
\text { behind rudders }\end{array}$ & 0.013 & 0.0090 & 0.0036 \\
\hline
\end{tabular}

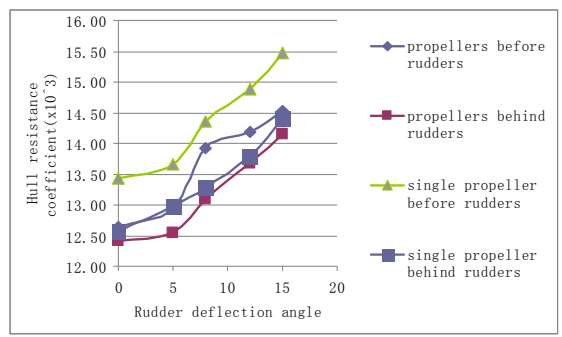

Figure 4. curves of hull resistance coefficient

\section{B. Propeller Performance Calculation.}

The numerical results based on simulation of the self propulsion condition in the auv with four rudders are given in Fig. 5-Fig.7. For completeness, the KQ and KT values under open water conditions are also plotted to facilitate a direct comparison of the coefficients under uniform wake and effected wake conditions.

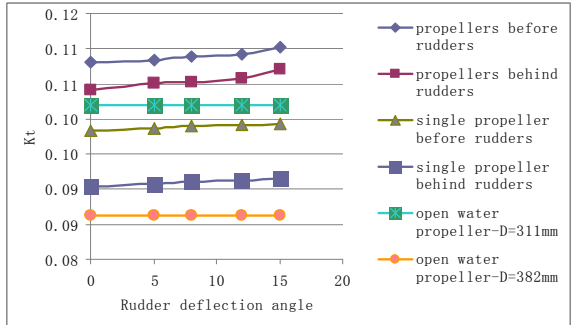

Figure 5. Thrust coefficient Kt of propellers

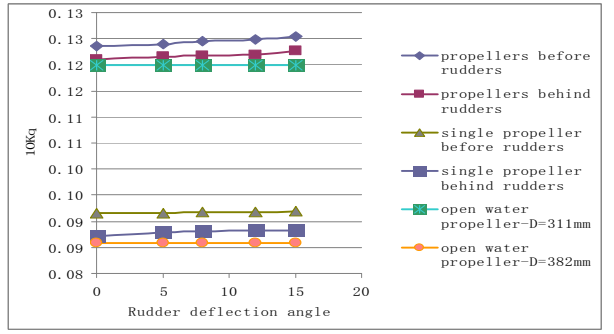

Figure 6. Torque coefficient Kq of propellers

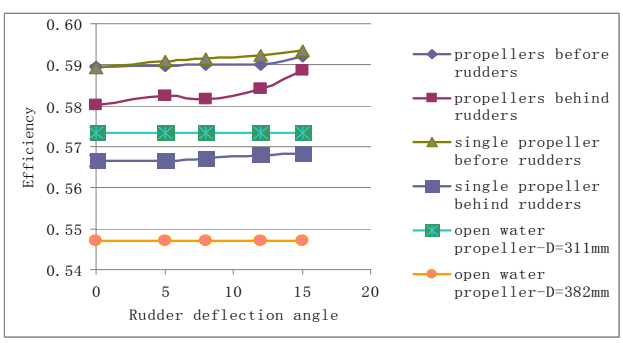

Figure 7. Efficiency of propellers

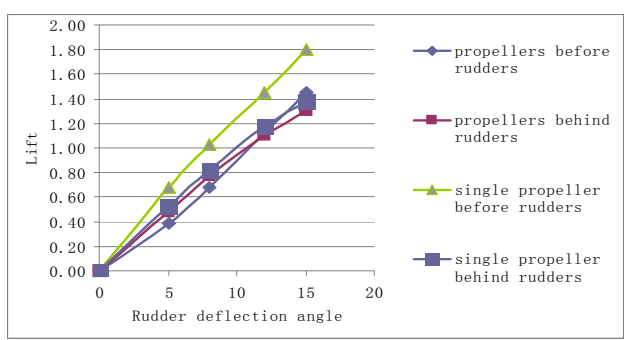

Figure 8. Lift of rudders

It is seen from Figure 5- Fig.7 that no matter what sort of arrangement, with the rudder angle increases, the coefficient of propeller will improve. Thrust coefficient KT , torque coefficient KQ and efficiency when propeller assigned before rudders were larger comparing to another condition.

In addition, coefficients of single one located after rudders is worse than pair propellers. Because of the larger diameter. But efficiency under the condition single propeller placed before rudders is significantly higher than the other cases. Propellers are designed on the same diagram with distrinct diameter and pitch ratio. If choose the same paddle just to change the diameter will lead to higher $\mathrm{Kt}$ and $\mathrm{Kq}$ but too bad efficiency under single propeller cases. Consequently, this article re-designed propeller to improve efficiency. 
So it can be obtained that the effect of rudder on propeller in the back of it is advantageous.In addition,playing rudder angle would form favorable interference on propeller.

Efficiency of a propeller behind the hull is better than working in open water.Turbulence in the flow is low in open water but in the behind condition the flow is turbulent and unsteady.Because flow around a propeller is affected by the presence of the hull which leading to the pressure distribution change of propeller blade surface and its back.

\section{Rudders Performance Calculation}

After successful validation for the ahead condition, it is desirable to examine the detailed rudder forces induced by the propeller to facilitate a better understanding of the propeller-hull -rudder interactions. Figure 9 is a comparison of the calculated rudder force. This paper considered only the horizontal rudders.

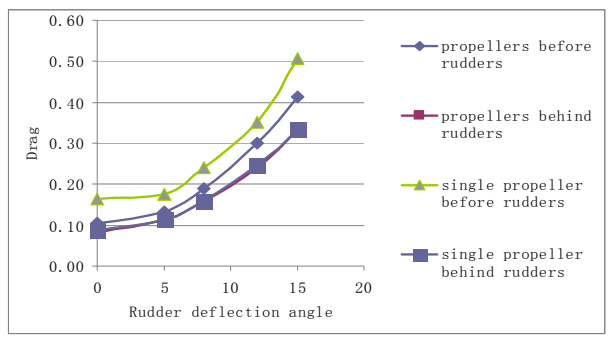

Figure9. Drag of rudders

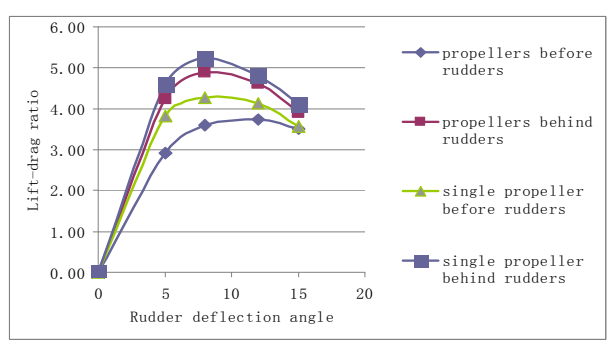

Figure 10. Lift-drag of rudders

The trend of each coefficient under four cases is analogous and lift-drag ratio highest in the vicinity of $8{ }^{\circ}$. Firstly, considering the cases of different installation position. When propeller is before, the lift is higher than another condition and the superiority is more clear with the angle increases. But its drag is also larger, so the ratio is contrary small. Comparing with double propellers cases, lift of single propeller conditions increases more and the resistance change a little. Therefore the lift-drag ratio higher all the better. It is thus clear that rudder effect is highest when a propeller located in front of rudders.

Analysis the above conclusion,we can see that with single larger diameter propeller,the boat resitance is higher but steerage is better.When propeller located before rudders,it will have a higher efficiency and bigger lift but resistance of hull and rudders increase and the lft-drag ratio becomes smaller.

\section{SUMMARY}

This paper simulates hull-propeller-rudder interaction under four different general arrangement conditions, and analysis on hull resistance, propeller thrust, torque and efficiency, rudder lift, drag and its ratio. Comparing of different designs, the advantages and disadvantages were summarized as follows. Arrangement of rudder and propeller is first considered, when rudder is behind propeller, this arrangement has the advantage of stronger thrust, higher efficiency, lower rudder drag, higher lift-drag ratio than the other method, but it will also increase body drag and decrease rudder lift. It is also inconvenience to assembling work, because extra frame is required to fix rudder. The other method is opposite. Number of propellers is then taken into consideration; propeller diameter can be reduced when double propellers method is selected, but propulsive efficiency is lower than single propeller, besides, propellers might be damaged, if particular protection is not taken, because they are out of hull range. All things considered, arrangement of single propeller and rudder behind are selected.

\section{REFERENCES}

[1] Dj.M. Maric, P.F. Meier and S.K. Estreicher: Mater. Sci. Forum Vol. 83-87 (1992), p. 119.

[2] M.N. Senthil Prakash,V. Anantha Subramanian:Simulation of Propeller - Hull Interaction Using Ranse Solver(International Journal of Ocean and Climate Systems 2010).

[3] Tae-hwan Joung, Karl Sammut, and Fangpo He:A CFD (Computer Fluid Dynamics) Analysis Based Design Method For An Autonomous Underwater Vehicle Ducted Propeller(The International Society of Offshore and Polar Engineers)

[4] John Carlton, Dejan Radosavljevic and Stewart Whitworth: Rudder Propeller - Hull Interaction: The Results of Some Recent Research, In-Service Problems and Their Solutions(First International Symposium on Marine Propulsors 2009).

[5] Yao Zhenqiu,Gao hui:Numerical Simulation of Interaction between Submarine and Propeller Based on Approach of Sliding Mesh. Journal of Jiangsu University of Science and Technology(Natural Science Edition) Vol.22 (2008),p.16.

[6] Wang Chao,Huang Sheng and Chang Xin:Research on the hydrodynamics performance of propeller-rudder interaction based on sliding mesh and RNG k- $\varepsilon$ model. Journal of Ship Mechanics Vol.15 (2011),p.716. 